\title{
Development of the Asphalt Multi-Integrated Roller Field and Experimental Studies
}

\author{
Abd El Halim Omar Abd El Halim, ${ }^{1}$ Amir Omar Abd El Halim, \\ Moustafa Awadalla, ${ }^{1}$ and Mohamed Adel Hassanin ${ }^{1}$ \\ ${ }^{1}$ Civil and Environmental Engineering Department, Carleton University, 1125 Colonel By Drive, Ottawa, ON, Canada K1S 5B6 \\ ${ }^{2}$ Infrastructure Management and Pavement Engineering Stantec, 49 Frederick Street, Kitchener, ON, Canada N2H 6M7 \\ Correspondence should be addressed to Abd El Halim Omar Abd El Halim; a_halim@carleton.ca
}

Received 26 June 2015; Accepted 6 September 2015

Academic Editor: Eric Lui

Copyright (C) 2015 Abd El Halim Omar Abd El Halim et al. This is an open access article distributed under the Creative Commons Attribution License, which permits unrestricted use, distribution, and reproduction in any medium, provided the original work is properly cited.

\begin{abstract}
Asphalt pavements have been compacted using steel drum rollers for a century. However, the problems that are observed today on these pavements are universal with no solution in sight. Intensive research work has been invested to identify the mechanisms that cause these problems. A recent development was the introduction of SuperPave mix design, GP asphalt cements, and the use of reinforcing elements ranging from polymer to steel bars. Yet it seems that none of these solutions have succeeded in eliminating any of the old problems. The pavements suffer from serious distresses regardless of the geographic location of the pavements and its design, materials, traffic loads, and climate condition. This paper presents a new approach to deal with the problems facing the asphalt pavements. While the research efforts to date concentrated on materials-related solutions, this paper identifies conventional compaction equipment as the cause of many problems observed on the pavements. The paper provides the development of the new Asphalt Multi-Integrated Roller, AMIR, and discusses new developments leading to a number of commercial field trials on several Ontario highways. The paper concludes that current compactors must be replaced with soft flat plates in order to achieve the required specifications for long term performance.
\end{abstract}

\section{Introduction}

The most important stage in the construction of asphalt pavements is the final operation of the compaction after which the road is opened for traffic. Current method of asphalt compaction consists of using two or three different rollers to achieve the required objectives. These objectives include higher and uniform densities, tight surface texture, and smooth level surface. The main compaction effort is achieved by either heavy vibratory or oscillating steel drum rollers. In many parts of the world this so-called "breakdown" stage is followed by a multiwheeled pneumatic roller and static steel roller to remove any defects or marks caused by the vibratory or oscillating rollers [1-4]. These rollers have been used in all or in part since the beginning of using asphalt mixes to build paved roads. The use of vibratory rollers was added in 1950 after Dynapac developed its vibratory rollers to provide additional effort to the compaction process $[5,6]$.
The traditional method of using rollers with steel drums for compacting hot asphalt mixes has been shown to induce numerous hairline cracks in the finished asphalt surface as can be seen in Figure 1 [7]. The industry has been treating the phenomenon of hair line cracking as a "cosmetic" one that has no subsequent effects on the long term performance of the finished pavement. This deficiency is normally dealt with by employing the multiwheeled pneumatic rollers which assume that the hairline cracks will be closed under the effect of kneading. The idea is that the "soft" rubber tires can "cure" or close the surface hairline cracks generated by steel roller compactors. Experimental research results carried out to examine this assumption provided strong evidence $[7,8]$ that the pneumatic roller does not close the resulting induced hairline cracks. In addition the results showed that these cracks can significantly reduce the tensile strength of the finished pavement. It was also evident that these surface induced cracks will lead to various types of distress such 


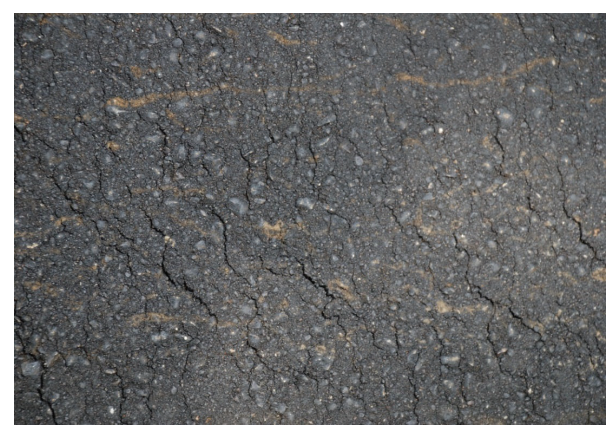

FIgure 1: Construction induced cracks.

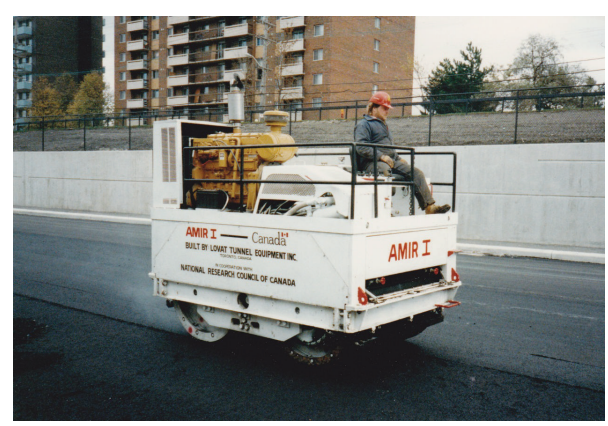

FIgURE 2: The new Asphalt Multi-Integrated Roller, AMIR I.

as stripping, transverse cracking, and potholes which can lead to the often reported early premature failure of newly constructed asphalt pavements.

In order to prevent the initiation of these construction cracks in the asphalt surface, a new compactor was designed and built in the early 1990s and has been developed and termed "Asphalt Multi-Integrated Roller," or AMIR. It was built based on the concept of relative rigidity and geometric compatibility $[7,8]$. This new concept of asphalt compaction was first tested in the laboratory at Carleton University and subsequently a large scale AMIR prototype, Figure 2, was built as a joint project between Carleton University, the Industrial Research Assistance Program (IRAP) of the National Research Council Canada (NRC), and a Canadian manufacturer, Lovat Tunnel Equipment Inc. [7].

The development of the prototype and its subsequent testing in the field has been reported in several research papers [7-13] and the main findings of that early stage are only summarized in this paper. The AMIR roller was further developed into an Australian version termed "HIPAC" [11] where it was used to compact commercial project in Australia as shown in Figure 3. However, due to lack of funds the Canadian AMIR prototype was not developed further and no more field trials were carried out.

In 2012, the Ministry of Transportation of Ontario expressed new interest in further developing the AMIR prototype. As a result of this new interest, an MoU between MTO and Carleton University was signed under which an Ottawa pavement contracting firm, Tomlinson Group, joined as the third party representing the pavement industry. The results of this agreement were the development and testing

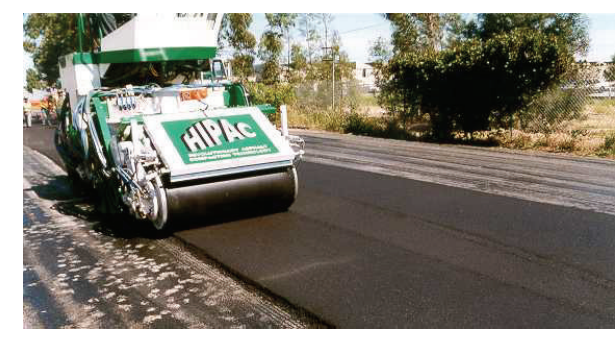

Figure 3: The Australian AMIR's version Hot Iron Principle Asphalt Compactor.

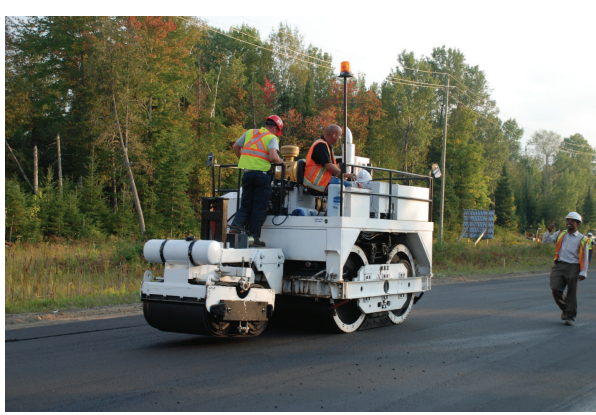

FIgURE 4: The upgraded AMIR II.

of the new generation AMIR II ML, Figure 4. This paper explains the AMIR compaction technique and presents a summary of the AMIR early field testing program and the main findings of the new field trials carried out on several major highways in Ontario using the new AMIR II ML.

\section{Conventional Compaction Method}

For almost 100 years today the asphalt pavements are constructed worldwide utilizing a train of vibratory steel drum roller, followed by multiwheeled pneumatic roller and finally a static steel drum roller. The rolling effect is combined with vibratory excitation of the steel drums in an effort to achieve higher density of the asphalt layer in short time. It is widely recognized that these types of compactors create hairline cracks parallel to the contact line of the drum or perpendicular to the rolling direction. The cause of these cracks can be easily explained and even visually observed during standard compaction processes.

A moving compactor with steel drums generates a wave of asphalt in front of the drum. This wave is caused by a pushing action of the drum, that is, by a large horizontal component of the contact pressure between the drum and the fresh asphalt. This pushing action in front of the drum results in a pulling action behind the drum; thus, the asphalt layer behind the drum is in tension. Close observations reveal that the asphalt immediately behind the steel roller has a tendency to rebound due to the elastic component of deformation. The tensile stress in combination with the elastic rebounding strain results in the initiation of surface and internal cracks in the asphalt. These deficiencies are further explained by incompatibilities in the geometry and materials 


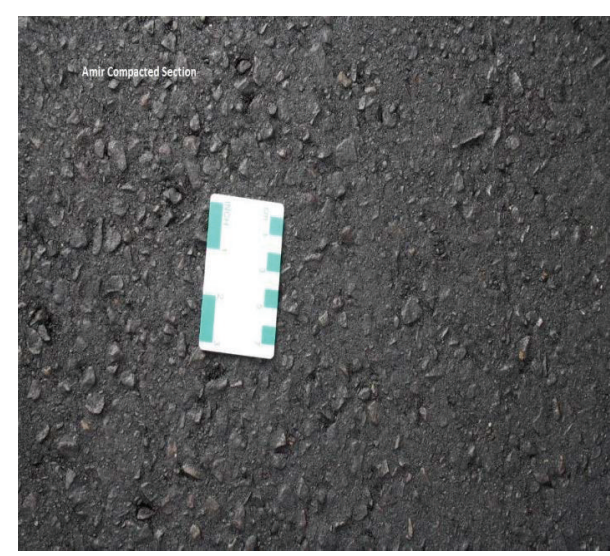

(a)

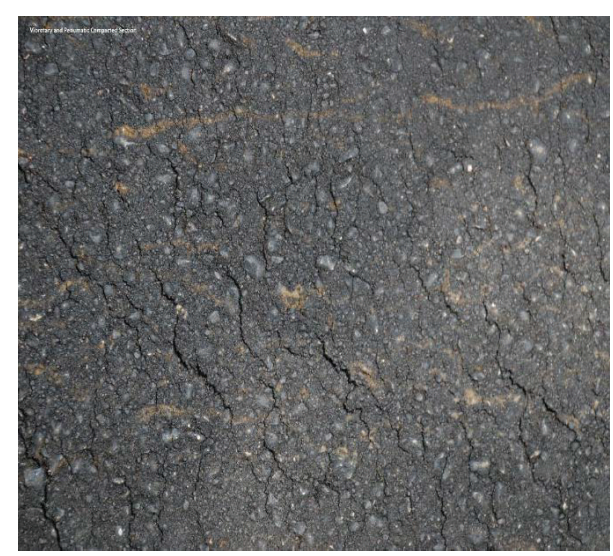

(b)

FIGURE 5: Comparison between the finished surface of the conventional compaction method (right) and advanced compaction method (left).

between the drum and the hot asphalt layer [12]. The problem of construction induced cracks is independent of the type and temperature of the asphalt mixture and it increases in its intensity with increased stiffness of the layer under the compacted asphalt mat which explains why these cracks can be observed more on asphalt decks on top of concrete bridges.

\section{Asphalt Multi-Integrated Roller, AMIR}

The geometric incompatibility of a standard, single drum is removed by using two large drums with an assembly of small rollers between them. In addition, a special type of rubber belt placed around the two large rollers also encompasses the small roller assembly to integrate them into what acts as "soft compacting plate." This system converts a circular contact between a single drum and the hot asphalt mix into a flat, plate type contact surface. Also, it transfers the applied pressure from a single line in the case of the steel drum into a rectangle area in the case of AMIR. These differences in the operating mechanisms of the current vibratory steel drum rollers and the AMIR compactor provide two significantly different compaction techniques, while the current compaction method relies on delivering its compaction effort through a rigid circular interface which will contact the softer asphalt mat in a relatively small area of contact (theoretically straight line) and applying very high impact vibratory load in a very short duration which will force the asphalt material to act in a more elastic mode. Thus, the uncompacted asphalt mat which lacks any tensile strength will tend to crack under these loading conditions. On the other hand, the AMIR concept allows a larger softer area of contact with asphalt mat which will provide relatively much smaller pressure during a much longer contact time which allows the viscoelastic-plastic asphalt mat to absorb more effectively the applied compaction effort and preventing the initiation of construction cracks. Field observations have shown that the AMIR does not generate a wave action in the asphalt. This is due to the fact that the contact pressure between the belt and the hot asphalt is mainly of a compressive nature. This pressure is also very small, as the weight of the AMIR is distributed over a large area. A close observation of AMIR compaction also reveals practically no rebound of the asphalt behind the AMIR. The assembly of small rollers between the two main rollers and the pressure of the rubber belt do not allow any upward relaxation of deformation between the main rollers.

\section{Summary of Previous Field Trials}

The first AMIR full scale prototype was designed and built in 1989 and a comprehensive experimental investigation was carried out to prove the validity of its premise. This program consisted of a number of field trials and subsequent laboratory testing on asphalt specimens recovered from the field. In all the paving field trials, the procedure included the AMIR compactor side by side with conventional rollers, so a realistic comparison between the new and the conventional compaction rollers was possible. The main objectives of this program were to prove that the AMIR compaction will produce compacted asphalt pavement with a crackfree surface, will achieve at least comparable and acceptable density and strength values, and can achieve the specified compaction requirements in equal or less number of passes when compared to currently used compaction method. A basis for such proof was field observations of AMIR compaction versus standard (Figure 5) and a detailed analysis of the quality of the compacted asphalt.

Four field trials have been carried out: one in Toronto, where paving over an aggregate base was done, and three in Ottawa on the NRC campus, where paving on top of an existing asphalt road (an overlay) was performed. In all these field trials the test sections were divided longitudinally into two 3-m wide halves (lanes). In each test section the AMIR prototype was used to compact its section while the other section was compacted by the conventional rollers: static or vibratory steel roller followed by a multiwheeled pneumatic roller. The evaluation protocol consisted of four standard tests: (a) the density test, (b) the tensile strength by an indirect tensile strength method, (c) the tensile strength by a direct method, and $(d)$ the flexural strength $[7,8]$. A large number of 
cores, slabs, and beams were extracted from the test sections for this purpose. The details of the data and analyses of the evaluation program can be found elsewhere [7-12] and only the summary of the main findings and conclusions are given below:

(i) The new AMIR compactor provided a crack-free surface with tighter texture.

(ii) The presence of the hairline "check" cracks was visible to the naked eye on the steel compacted pavement even after several passes of the multiwheeled pneumatic roller.

(iii) The construction cracks influenced the mechanical properties of the asphalt in addition to resulting in high values of permeability.

(iv) The AMIR compactor met the required specifications in less number of passes.

(v) AMIR compacted pavements have more uniform density distribution.

(vi) With the elimination of surface cracks, the new compaction method provided pavement with higher strength.

(vii) The expected productivity is higher than the productivity of today's technology.

(viii) The AMIR compactor completed the compaction job without the need of any additional rollers which required 3 different rollers when conventional equipment is used.

Tables 1-4 provide some of the results obtained from tests carried out during the period between 1989 and 2004 . There were several countries and heavy equipment firms which showed interest in the new technology during that period. The Australian road firm Pioneer Road Services, Dynapac of Sweden, and Caterpillar of USA were among the organizations that were interested in the AMIR technology. The Australian firm in cooperation with Carleton University designed and built the second AMIR generation "HIPAC" which was used on commercial basis by the firm. During the time of AMIR development USA SuperPave system which was one of SHRP outcomes drew the attention of the paving industry. It was expected that the application of the SuperPave technology especially the new asphalt mixes and the adoption of the Gyratory compaction to design the mixes will help reducing many of the old problems observed on the asphalt pavements of the world. As a result, interest in the AMIR technology was winding down on the hope that there will be no need to it.

\section{Revival of the AMIR Technology}

It was not until around 2011 that the Ministry of Transport of Ontario showed serious interest to reconsider the revival of the AMIR technology which may have been the result of the fact that the old problems appear to remain in spite of all the improvements offered and expected from the introduction of SuperPave. The Ministry signed an MoU with Carleton
TABLE 1: Summary of calculated densities.

\begin{tabular}{lcccc}
\hline Location & \multicolumn{2}{c}{ AMIR } & \multicolumn{2}{c}{ Conventional } \\
& Mean & $\begin{array}{c}\text { Standard } \\
\text { deviation }\end{array}$ & Mean & $\begin{array}{r}\text { Standard } \\
\text { deviation }\end{array}$ \\
\hline Edge & 2.412 & 0.012 & 2.392 & 0.012 \\
Middle & 2.427 & 0.013 & 2.411 & 0.015 \\
Centre & 2.437 & 0.017 & 2.422 & 0.008 \\
All cores & 2.425 & 0.017 & 2.408 & 0.017
\end{tabular}

A total number of cores were $96 ; 48$ from each section

TABLE 2: Indirect tensile strength (MPa).

\begin{tabular}{lcccc}
\hline Location & \multicolumn{2}{c}{ AMIR } & \multicolumn{2}{c}{ Conventional } \\
& Mean & $\begin{array}{c}\text { Standard } \\
\text { deviation }\end{array}$ & Mean & $\begin{array}{r}\text { Standard } \\
\text { deviation }\end{array}$ \\
\hline Edge & 0.667 & 0.051 & 0.587 & 0.045 \\
Middle & 0.708 & 0.060 & 0.636 & 0.068 \\
Centre & 0.703 & 0.057 & 0.731 & 0.066 \\
All cores & 0.692 & 0.059 & 0.645 & 0.079 \\
\hline
\end{tabular}

TABLE 3: Direct tensile strength (MPa).

\begin{tabular}{lcc}
\hline Location & AMIR & Conventional \\
\hline Edge & 0.402 & 0.316 \\
Middle & 0.385 & 0.329 \\
Centre & 0.426 & 0.481 \\
All slabs & 0.404 & 0.375
\end{tabular}

Average of two slab tests per location per compaction method

TABLE 4: Flexural strength (MPa).

\begin{tabular}{lcc}
\hline Temperature $\left({ }^{\circ} \mathrm{C}\right)$ & AMIR & Conventional \\
\hline 18 & 1.34 & 0.87 \\
0 & 5.09 & 4.58 \\
-20 & 4.99 & $4 / 75$ \\
-40 & 4.09 & 3.44 \\
\hline
\end{tabular}

University and an Ottawa Paving contracting firm to upgrade and improve the AMIR I compactor and try it on a number of commercial projects including several Ontario highways and bridge decks on one of its highways.

The result was the AMIR II ML which was a much improved compactor than its predecessor AMIR I in several areas including steering and maneuverability, hydraulics, controls, and the rubber belt. A comprehensive testing program was carefully planned and executed which included in addition to the highway and bridge sections a number of in-house tests on several sites owned by the paving firm Tomlinson in the city of Ottawa to ensure its proper mechanical and functional operations. The following sections provide summary of the highway tests, their locations, and type of tests conducted, description of the in-house tests, and discussion of the main findings of the tests performed to date. 


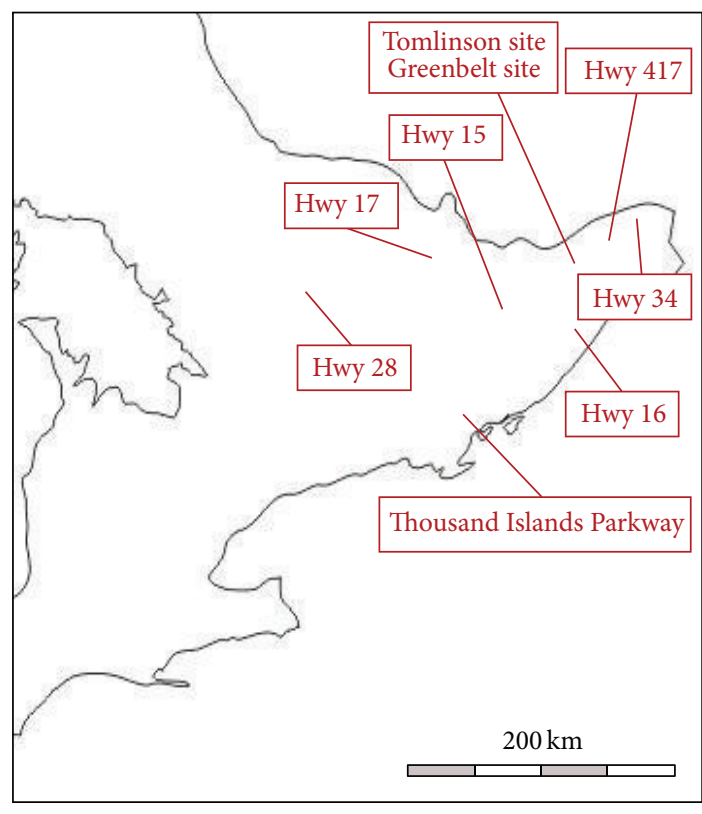

FIGURE 6: Site locations in Eastern Ontario.

\section{Field Tests of AMIR II ML}

Several sites including highway projects and in-house field trials in Ontario's Eastern Region were selected for inspection, testing, and sampling immediately after the paving and the compaction stages are completed. The term "inhouse" is used in this research to refer to non-highway-field projects performed at controlled locations/sections under the supervision of the Ottawa-based construction firm R. W. Tomlinson Limited. Figure 6 illustrates the location of each HMA highway project or in-house field trial included in the most recent study. The selected sites represent different asphalt design mixtures that are used by the MTO in order to ensure the diversity and generalities in the collected data. The main objectives of these tests were to ensure that the AMIR compactor can compact the SuperPave HMA which is stiffer than the mixes used in the late 80 s and 90 s, to examine its ability to provide the same crack-free surfaces, and to lower permeability values when compared to same asphalt pavements compacted by conventional method.

Several investigations were carried out to evaluate the performance of the two compaction methods based on results obtained from common sites only where the two compaction methods were used side by side. These sites were Thousand Islands Parkway, the bridge on Highway 34, Tomlinson inhouse field trial, and Greenbelt Yard. Different pavement characteristics including field and laboratory permeability, relative density, and indirect tensile strength were used for the comparison. For each characteristic, the average value per test location (the location where the core was extracted) was computed and categorized by the compaction method as shown in Figure 7.

As can be seen from the field permeability results summarized in Figure 7(a), the observed trend for the conventional method suggests that the two edges had higher average
TABLE 5: Summary of the null and alternative hypotheses.

\begin{tabular}{lll}
\hline Pavement characteristic & \multicolumn{2}{c}{ Test hypotheses } \\
& Null & Alternative \\
\hline Field permeability & $\mu_{\text {conventional }}=$ & $\mu_{\text {conventional }} \neq$ \\
Lab permeability & $\mu_{\text {advanced }}$ & $\mu_{\text {advanced }}$ \\
Relative density & & \\
Indirect tensile strength & & \\
\hline
\end{tabular}

TABLE 6: Summary of the one-way ANOVA results for the common sites.

\begin{tabular}{lcc}
\hline Pavement characteristic & $F$ & $P$ value \\
\hline Field permeability & 17.752 & $<0.001$ \\
Lab permeability & 4.253 & 0.044 \\
Relative density & 8.675 & 0.004 \\
Indirect tensile strength & 4.311 & 0.042 \\
\hline
\end{tabular}

permeability than the middle location. The advanced method (or AMIR) showed that there was a gradual reduction in average permeability as moving from the inner edge to the outer edge. In all cases, it is quite evident that the field permeability values for the conventional method were higher than those of the advanced method. Figure 7(b) suggests that there was an obvious decrease in average lab permeability values where the outer and inner edges experienced relatively high permeability compared to the middle locations. This observation holds true for the two compaction methods. In addition, the presented results imply that the field-recovered cores obtained from road sections finished by the advanced method are, on average, less permeable in all considered locations compared to the conventional method. The bar chart presented in Figure 7(c) shows that the relative density produced by the conventional method decreases gradually as moving from the middle location towards the two lane edges. For the advanced method, it was found that the average density is higher at the inner middle and outer middle locations compared to the other three locations. According to the indirect tensile strength results shown in Figure $7(\mathrm{~d})$, the conventional method showed less strength in the inner and outer middle locations while the other three locations were almost equal. The advanced method exhibited a different trend where the indirect tensile strength values are higher in the three middle locations compared to the two edges.

For the same dataset, a one-way analysis of variance (ANOVA) test was also conducted to investigate if there is a significant difference between the mean values for each pavement characteristic for the two compaction methods. The null and alternative hypotheses for each property are shown in Table 5 .

According to the ANOVA results summarized in Table 6, it can be seen that all $p$ values were less than $5 \%$ for all pavement characteristics, and thus the null hypothesis was rejected. This indicates that there was a significant difference between the two compaction methods in terms of the four considered pavement characteristics when examining the common sites between the two compaction methods. 


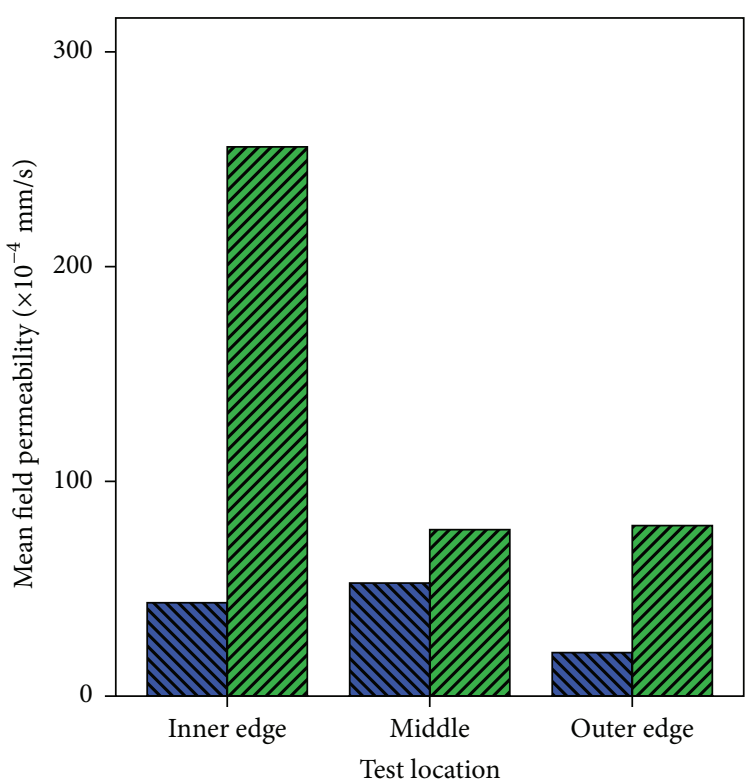

Compaction method

A Advanced

G Conventional

(a) Field permeability

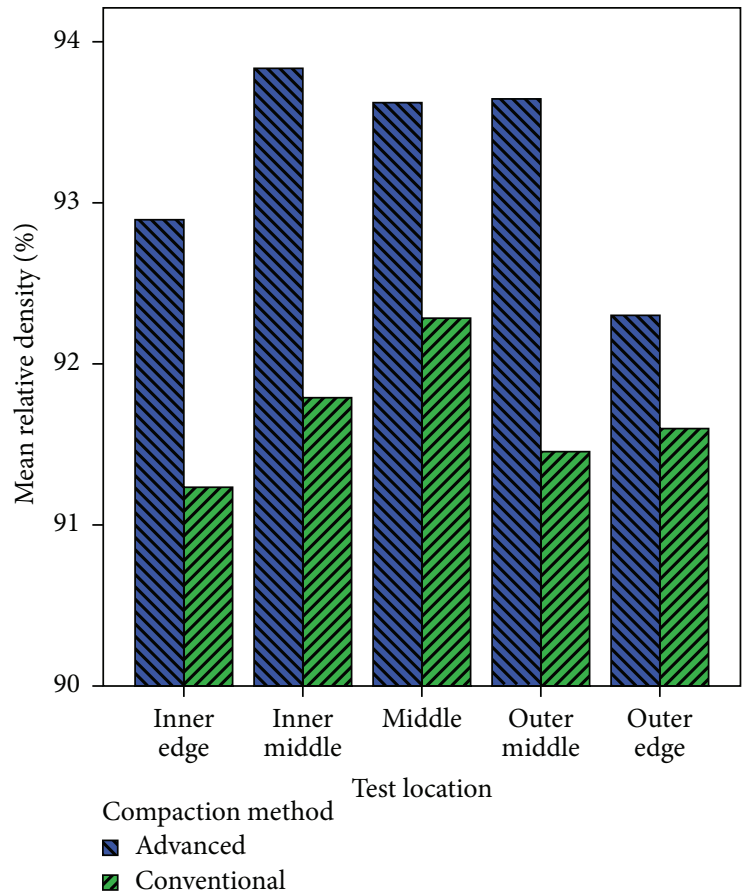

(c) Relative density

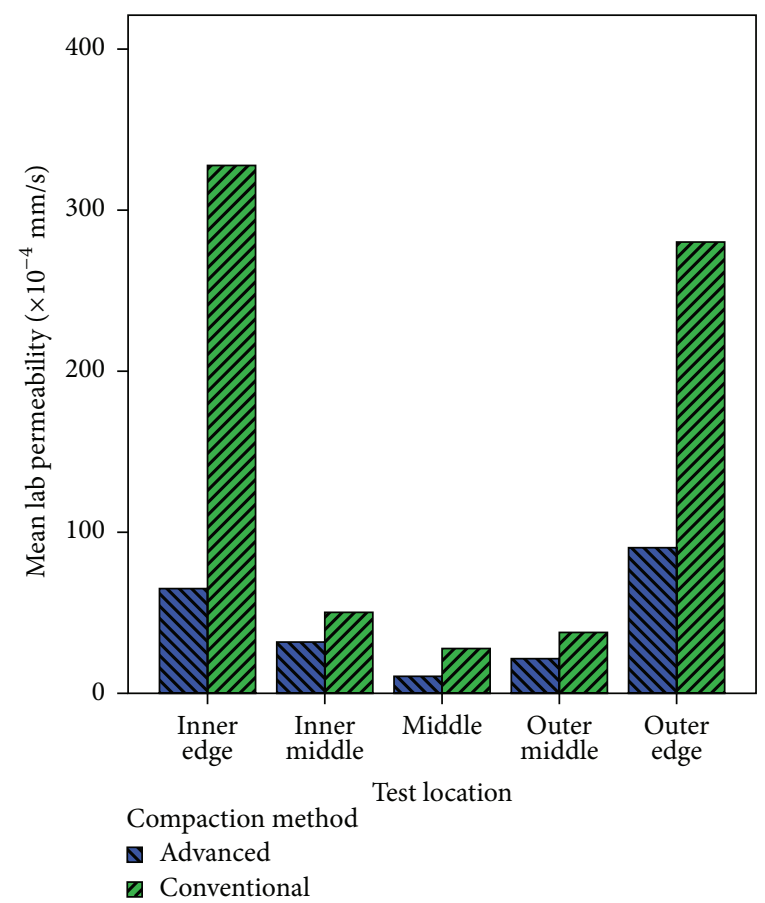

(b) Lab permeability

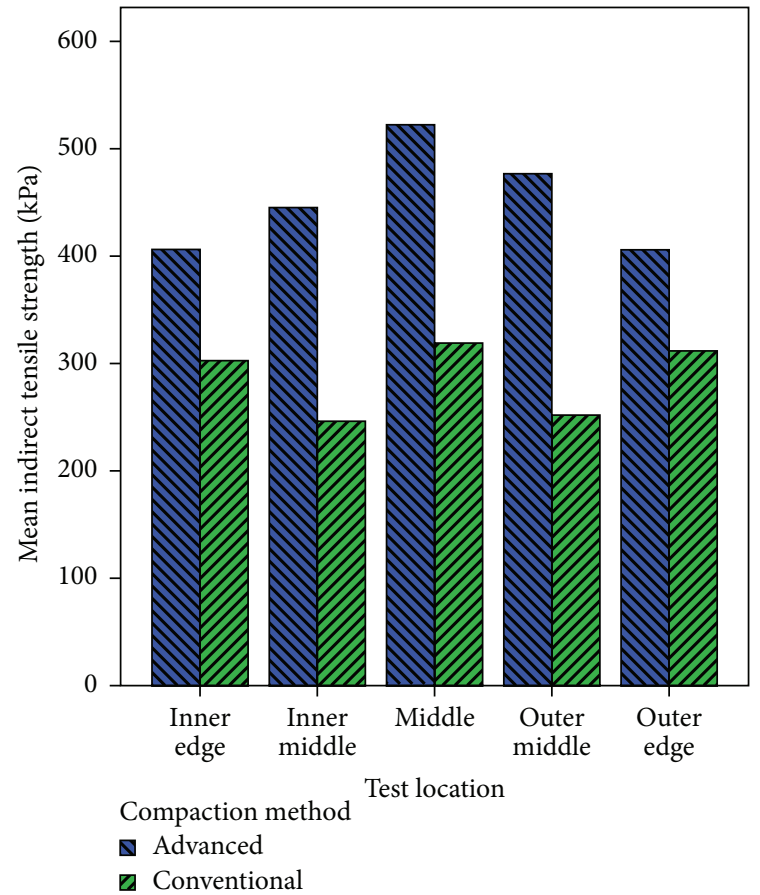

(d) Indirect tensile strength

FIGURE 7: Comparison between the compaction methods in terms of the four pavement properties.

\section{Conclusions}

The first phase of the development of the AMIR compaction technique was completed during the period between 1989 and 2007. The validity of the AMIR concept has been proven through a comprehensive field and laboratory testing investigation. In all field trials the AMIR compactor was tested side by side with the conventional compaction equipment. By the end of the first phase Australian paving firm was convinced that the new AMIR technology has a promising potential to provide superior asphalt pavements. As a result a second more capable new roller termed HIPAC was designed, built, and used on commercial projects in Australia. The recent upgrading and improvements of the Canadian AMIR 
compactor led to its utilization on several MTO highway projects including the compaction of a highway bridge deck under cold temperature $\left(-7^{\circ} \mathrm{C}\right)$. The results and analysis presented in this paper support the following conclusions:

(1) In all field trials and regardless of the type of the asphalt mix and the type of foundations the AMIR compactor achieved all the required specifications of the finished pavement.

(2) The AMIR compactor achieved equal or higher and uniform densities of the compacted asphalt sections with less number of passes compared to the number of passes completed by the conventional equipment.

(3) The overall quality of the AMIR compacted asphalt concrete pavements is better than that compacted by a standard method including crack-free surface with tighter texture.

(4) The recent improvements resulted in solving some of the problems associated with the compaction of polymer asphalt mixes especially sticking with the rubber belt of AMIR.

(5) In all field trials AMIR compacted pavements produced significantly less permeability values than those measured on pavements compacted with steel and pneumatic rollers.

(6) All AMIR compacted sections were completed using only one AMIR unit compared with the 3 rollers used by conventional method.

Finally, while the AMIR compactor used in the past and today is still a prototype its technique represents a major innovation in asphalt compaction. The problems often observed on paved roads have not been solved in spite of the development of new asphalt mixes, advanced design methods, and the use of reinforcing techniques. This paper provides a different approach to deal with the traditional problems that our roads have been suffering for the past 100 years.

\section{Conflict of Interests}

The authors declare that there is no conflict of interests regarding the publication of this paper.

\section{Acknowledgments}

The financial and technical support for this research project provided by the Natural Sciences and Engineering Research Council (NSERC), Ministry of Transportation of Ontario (MTO), Carleton University, and the technical support of R. W. Tomlinson Group Limited is greatly acknowledged and appreciated.

\section{References}

[1] C. Blades and E. Kearney, Asphalt Paving Principles, Cornell Local Roads Program-New York LTAP Center, Ithaca, NY, USA, 2004.
[2] H.-J. Kloubert, Basic Principles of Asphalt Compaction: Compaction Methods, Compaction Equipment, and Rolling Technique, BOMAG FYAT Group, 2009.

[3] D. Starry, Rolling Patterns to Achieve Density and Production, Volvo Construction Equipment, Shippensburg, Pa, USA, 2007.

[4] D. W. Starry Jr., "Vibratory rollers," in Factors Affecting Compaction of Asphalt Pavements, Transportation Research Circular, Number E-C105, pp. 36-48, Transportation Research Board, 2006.

[5] Y. Nose, "Vibratory pneumatic tire roller," in Factors Affecting Compaction of Asphalt Pavements, Transportation Research Circular, Number E-C105, pp. 54-68, Transportation Research Board, 2006.

[6] E. J. Kearney, "Oscillatory compaction of hot-mix asphalt," in Factors Affecting Compaction of Asphalt Pavements, Number EC105, pp. 49-53, Transportation Research Circular, 2006.

[7] A. O. Abd El Halim and O. J. Svec, "Influence of compaction techniques on the properties of asphalt pavements," in Proceedings of the 35th Annual Conference of the Canadian Technical Asphalt Association (CTAA '90), pp. 18-33, Winnipeg, Canada, November 1990.

[8] A. O. Abd El Halim, W. A. Phang, and R. C. Haas, "Unwanted legacy of asphalt pavement compaction," Journal of Transportation Engineering, vol. 119, no. 6, pp. 914-932, 1993.

[9] I. Rickards, S. Goodman, J. Pagani, A. O. Abd El Halim, and R. Haas, "Practical realization of a new concept for asphalt compaction," Transportation Research Record, vol. 1654, pp. 2735, 1999.

[10] A. O. Abd El Halim, R. Haas, and O. J. Svec, "Improved asphalt performance through a new method of compaction," in Proceedings of the 17th Australian Road Research Board Conference, vol. 3, pp. 177-192, Gold Coast, Australia, August 1994.

[11] A. E. O. Abd El Halim, D. Said, and A. Mostafa, "A protection of the environment through the prevention of surface cracking," The Open Civil Engineering Journal, vol. 3, no. 1, pp. 7-15, 2009.

[12] A. O. Abd El Halim, "Influence of relative rigidity on the problem of reflection cracking," Transportation Research Record, vol. 1007, pp. 53-58, 1985.

[13] A. O. Abd El Halim, F. Pinder, A. Chelliah, and O. Abdelalim, "Reducing maintenance and rehabilitation costs through the use of AMIR compaction," Civil Engineering and Architecture, vol. 1, no. 3, pp. 51-60, 2013. 

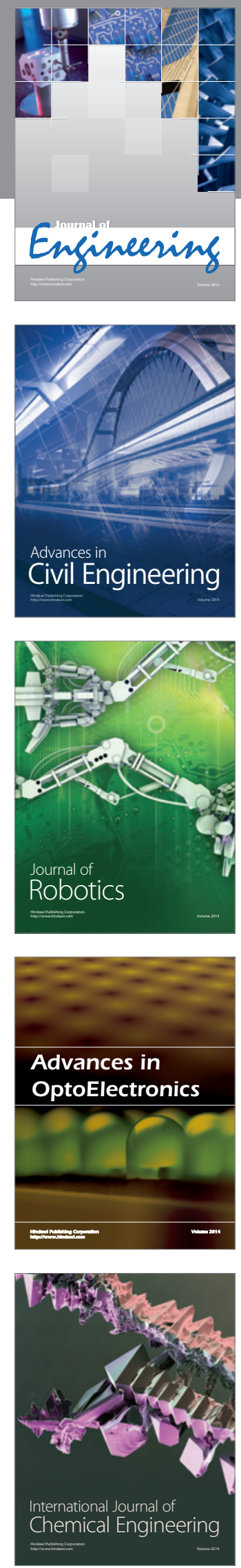

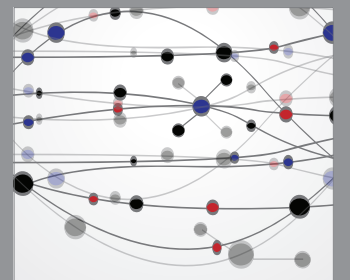

The Scientific World Journal
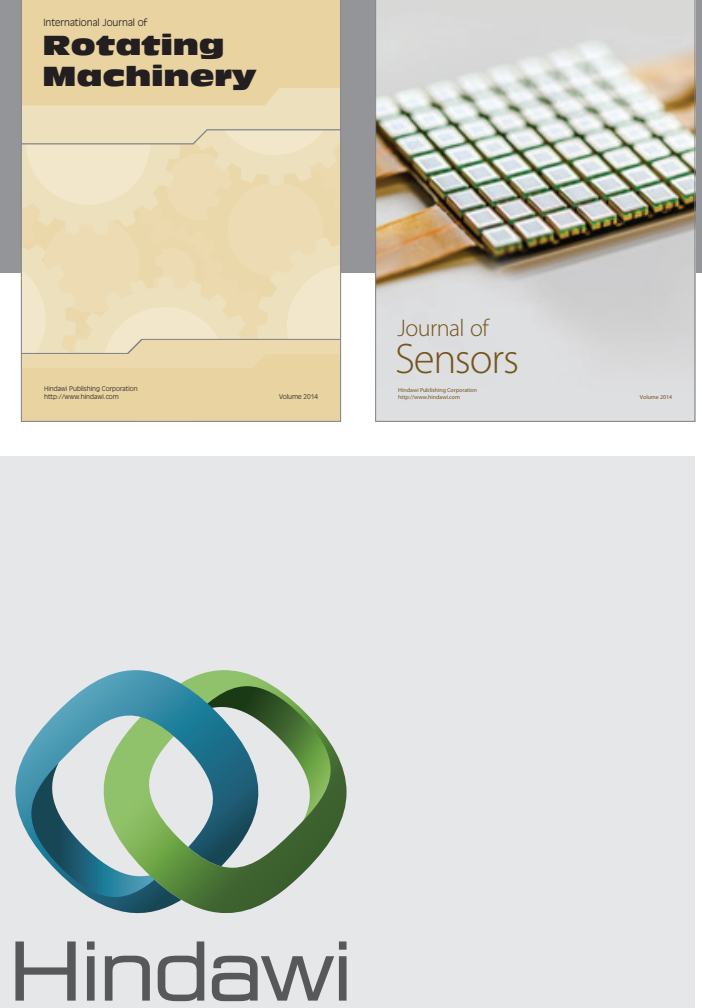

Submit your manuscripts at http://www.hindawi.com
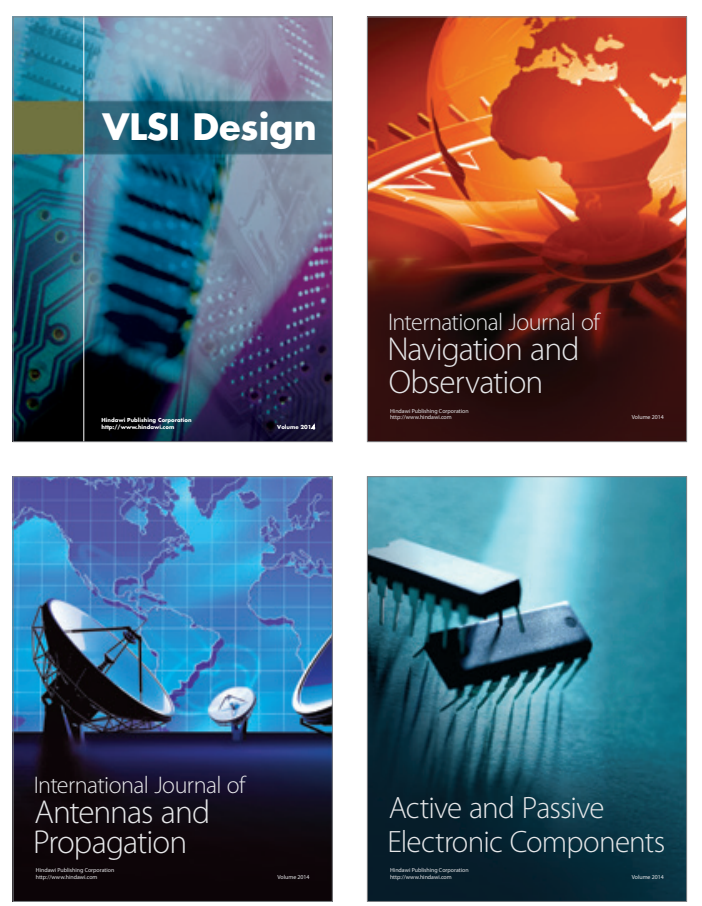
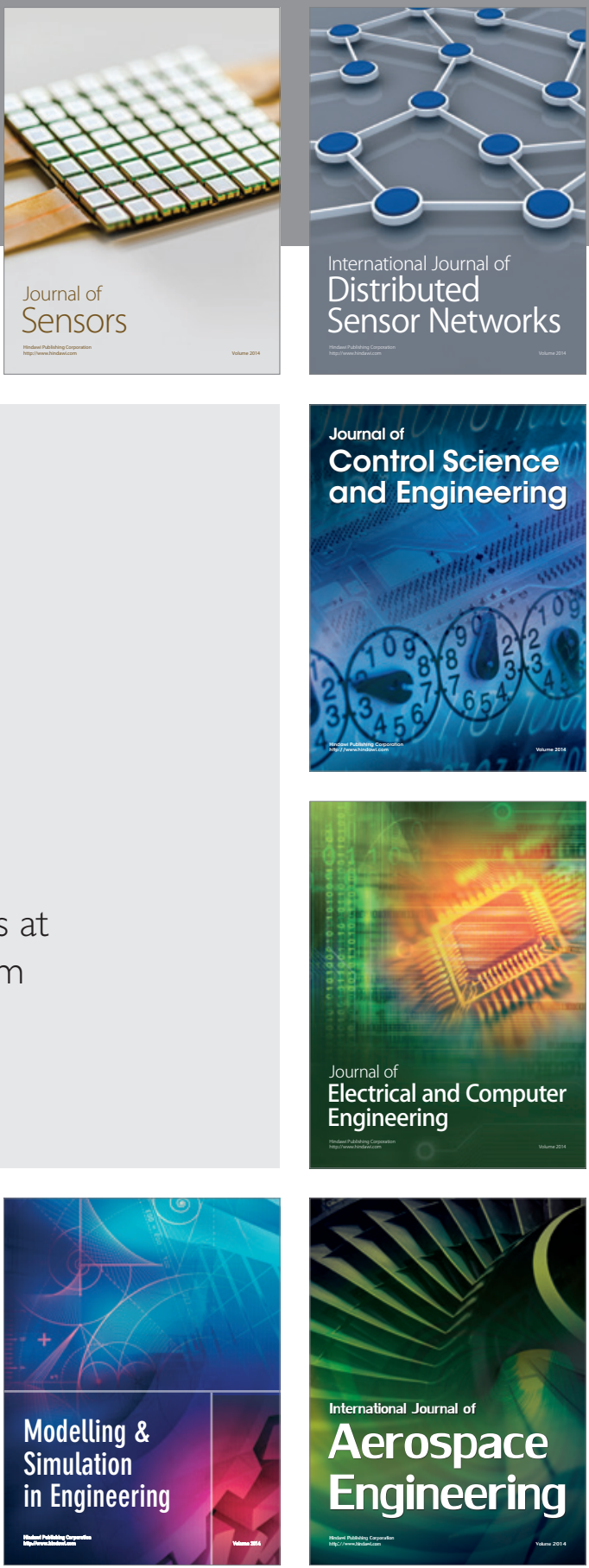

Journal of

Control Science

and Engineering
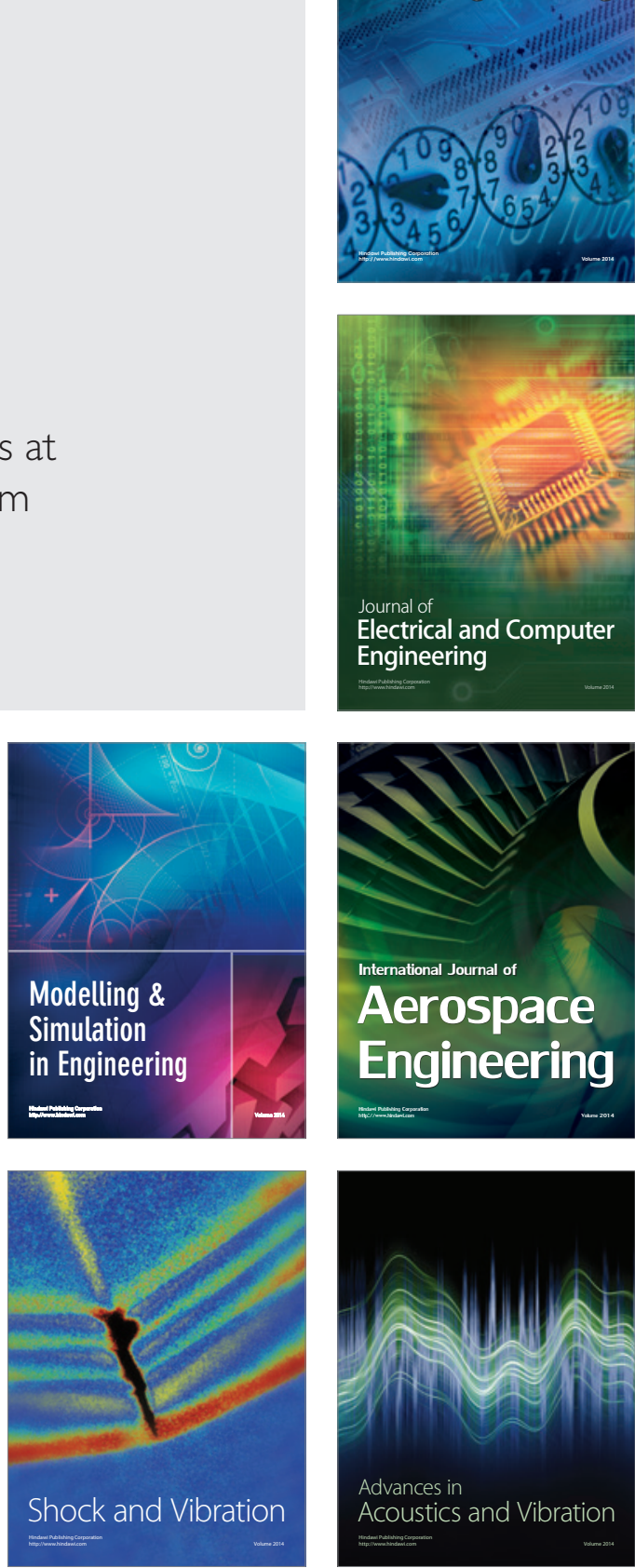